\title{
Evaluating the Preparedness of Child Health Facilities and Health Care Providers to COVID 19 Pandemic
}

\author{
Abideen Salako1, Oluwatosin Odubela ${ }^{1}$, Tomilola Musari-Martins ${ }^{1,}$,, Zaidat Musa ${ }^{2}$, \\ Titilola Gbaja-Biamila ${ }^{1}$, Babasola Opaneye ${ }^{1}$, David Oladele ${ }^{1}$, Priscilla Ezemelue ${ }^{1}$, Harry Ohwodo ${ }^{1}$, \\ Oliver Ezechi ${ }^{1}$, Agatha David ${ }^{1}$ \\ ${ }^{1}$ Clinical Sciences Department, Nigerian Institute of Medical Research, Lagos, Nigeria \\ ${ }^{2}$ Monitoring and Evaluation Unit, Nigerian Institute of Medical Research, Lagos, Nigeria
}

Email address:

tommigeorge@yahoo.com (T. Musari-Martins)

${ }^{*}$ Corresponding author

\section{To cite this article:}

Abideen Salako, Oluwatosin Odubela, Tomilola Musari-Martins, Zaidat Musa, Titilola Gbaja-Biamila, Babasola Opaneye, David Oladele, Priscilla Ezemelue, Harry Ohwodo, Oliver Ezechi, Agatha David. Evaluating the Preparedness of Child Health Facilities and Health Care Providers to COVID 19 Pandemic. European Journal of Preventive Medicine. Vol. 8, No. 5, 2020, pp. 91-96. doi: $10.11648 /$ j.ejpm.20200805.16

Received: September 10, 2020; Accepted: October 9, 2020; Published: October 17, 2020

\begin{abstract}
The challenges of diagnosis of SARS-CoV2 infection in the paediatric population includes not only the mild nature of the disease, but the similarity in the symptomatology of the COVID-19 disease to common childhood illness, and the possibility that the infected children could be "silent transmitters" to the family members and health care workers [HCW]. The challenge raises the doubt on the level of preparedness, awareness of the child health facilities [HCF], and HCW in adopting measures at combatting the Coronavirus disease 2019 (COVID-19) pandemic. This study evaluated the preparedness and response of HCF and HCW in paediatric settings to the 2019-novel coronavirus pandemic. A cross-sectional study involving child HCF and HCW. An online tool was used to evaluate preparedness for the management of infectious disease outbreaks as typified by the COVID-19 Outbreak. The information collected included demographic characteristics of the health personnel providing care for children, infection control practices, knowledge, and preparedness for prevention of COVID-19. Data generated were analyzed using the SPSS version 23.0. A majority of respondents were medical doctors (89\%), practicing for $>5$ years (75\%), and in public health care facilities $(69 \%)$. A significant proportion of the health facilities had an infectious disease unit $(68 \%)$ and policy on disease outbreak (60\%) in place. 144 (96\%) respondents knew SARS-CoV-2 was responsible for COVID-19 and the incubation period was an average of $2-14$ days. Most of the respondents were aware that the disease could be with or without symptoms $(86 \%)$, as well as mimic other childhood illnesses (93\%). Most of the centres (55\%) had fair policy strength towards combating the disease. IPC policies have been established in most paediatric facilities to combat the recurring threat of communicable disease outbreaks. There is a need for further scaling up of resources to address the COVID-19 pandemic.
\end{abstract}

Keywords: Preparedness, Health Facilities, Coronavirus Disease

\section{Introduction}

The Global community continues to experience several disease outbreaks including Zoonotic diseases with the African continent not left out. Zoonotic diseases such as the Ebola virus, have had a significant impact on humans [1-4]. These outbreaks have continued to test the preparedness of the health systems $[5,6]$. This is despite the proposed continuous multi-sectorial, transdisciplinary public health agenda of "One Health" [7].

The present pandemic of novel Coronavirus Disease-19 (COVID-19) caused by the Severe Acute Respiratory Syndrome Coronavirus 2 (SARS-COV2] is an outbreak that has once again questioned the preparedness of the health system for disease outbreaks [8]. Since COVID-19 was first reported in the Hubei province, Wuhan, China in December 2019, affecting persons of all ages, the aged and individuals with underlying co-morbid illness being most severely affected [9-11]. 
Nigeria, with a population of over 200 million citizens [12], has also reported cases of the COVID-19. The nation has reported about 238 confirmed cases, 5 deaths as at 6 th April 2020 since the first confirmed case on the 21st March 2020 [13]. Although the nation has fared well combating the pandemic, the health successes could be undermined with significant impact on the health indices of children with respect to morbidity and mortality [14].

Reports on the COVID-19 outbreak have largely been silent on children. This is open to questions: "are children dying unrecognized? or is the incidence and severity truly low in the paediatric age group?". Thus, there is a need for further clarification on the burden of the disease in children, the preparedness of the child health care provider, and the facilities to the disease outbreak.

The challenges of diagnosing SARS-CoV-2 infection in the paediatric population includes not only the mild nature of the disease, the non-specific nature of symptoms similar to common childhood illness [ranging from acute respiratory tract infection [ARI], acute diarrheal disease] and the possibility that the infected children could be "silent transmitters" to family members and Health Care Workers (HCWs) who in the course of examining and caring for them are exposed to aerosols and droplets [15]. The afore-mentioned challenges affect the early and prompt diagnosis of the SARS-COV2 infection in children.

The challenge raises the doubt on the level of preparedness of child health facilities and health care providers in adopting measures at combatting the COVID-19 pandemic. This study aims to evaluate the preparedness and response of health facilities and the health care providers in paediatric settings to the 2019-novel coronavirus pandemic.

\section{Methods}

This was a cross-sectional study involving health facilities providing health care services to children. An online tool was used to evaluate the preparedness of health workers and health facilities providing paediatric services for the management of infectious diseases outbreak as typified by the COVID-19 Outbreak. The tool was in four sections which included (a) Socio-demographic data, the duration of practice, levels of practice;( b) Facility Preparedness- Availability of an isolation room/wards, training, and policies on infectious disease control, the establishment of the COVID-19 response team; (c) Knowledge of disease outbreakPrevious experience of infectious disease outbreak, steps to Infection Prevention Control [IPC] and (d) Knowledge and Awareness on COVID-19-causative agent, symptomatology, diagnostic criteria for suspected and confirmed cases. The aggregate scores were calculated for each participant based on their responses to the questions in sections $\mathrm{B}, \mathrm{C}$, and $\mathrm{D}$. One point was allocated for correct answers, and in questions, with multiple answers, one point was awarded for each correct answer provided. No point was awarded for wrong answers, and participants were also awarded no points overall if any wrong answer was selected in questions that required multiple answers. No point was awarded if no answers were provided. The total scores for sections B, C, D were 38,13 , and 28 respectively, making a total of 79 points for the three sections. Data generated from the online survey was exported to Excel spreadsheet and cleaned. The analysis was done using SPSS version 23.0. Categorical data were summarized using proportions, normally distributed data were presented as mean with standard deviation, while the skewed data were summarized as median with interquartile range. Ethical approval was obtained from the Institution Research Ethics Boards (IRB) of the Nigerian Institute of Medical Research. Confidentiality was ensured as participants' personalized data were de-identified.

\section{Results}

One hundred and forty-eight (148) healthcare workers working in paediatric facilities participated in the online survey. The mean $( \pm$ SD) age of the respondents was $38.7( \pm 9.5)$ years with the male to female distribution of $0.5: 1$. One hundred and thirty-one (89\%) were medical doctors, $75 \%$ have been in medical practice for >5years, and the majority of the respondents $(69 \%)$ are in public health care facilities. Ninetyfour $(64 \%)$ respondents were in the tertiary level while $54(36 \%)$ secondary level of paediatric health care services. Most of the respondents $(58 \%)$ were working in facilities with $>15$ paediatric beds, $72 \%$ had emergency children ward and $65 \%$ had an isolation ward. Fifty percent of the respondents had experienced a disease outbreak in the past. (table 1)

Concerning infectious diseases unit [IDU]; $68 \%$ had an IDU, $60 \%$ had an existing policy on disease outbreaks. Among respondents with existing infectious disease policy, $43 \%$ acknowledge training on preparedness was done. The frequency of training was quarterly (43\%), annually (30\%), bi-annually $(11 \%)$ and as required [depending on need] $(16 \%)$. Most of the respondents $(75 \%)$ had a fair rating of the IPC policy and facility support with the majority of the respondents being aware of the steps of IPC (99\%). (table 2)

Concerning COVID-19, 144 (97\%) of the respondents knew that COVID-19 is caused by SARS-CoV-2. 142 (96\%), $128(86 \%)$ were aware the incubation period was a range of 2-14days and the disease could be with or without symptoms respectively, while $93 \%$ of the respondent understood the disease could mimic other childhood illnesses. $89 \%$ of the respondent had a good knowledge of the diagnostic criteria, though only $24 \%$ had a good knowledge of the care of children. Furthermore, $113 \quad(76 \%)$ had a COVID-19 management policy and most of the respondents (55\%) had a fair rating of the policy. (table 3 )

The presence of children emergency ward/room (OR; 4.4, CI: 2.0-9.4, $\mathrm{p}=0.01$ ), isolation ward (OR; 4.4, CI: 2.1-9.2, $\mathrm{p}=0.01$ ), IDU (OR: 6.4, CI: $3.0-13.7, \mathrm{p}=0.01$ and COVID-19 teams in public health care services (OR; 6.0, CI: 2.8-12.9, $\mathrm{p}=0.01$ ) were statistically significant compared to private institutions. (table 4)

In addition, children emergency ward/room (OR: $8.5 \mathrm{CI}$ : 3.8-19.2, $\mathrm{p}<0.05)$, Isolation ward (OR; $4.1 \mathrm{CI}$ : 2.0-8.4, $\mathrm{p}<0.05$ ), IDU team (OR: 16.4, CI: 7.0-38.5, $\mathrm{p}<0.05)$, COVID team (OR; $9.1 \mathrm{CI}$ : 4.19.6, $\mathrm{p}<0.05$ ), and policy (OR; $1.7 \mathrm{CI}$ : $0.8-3.6, \mathrm{p}<0.05$ ), were found to be statistically significant in tertiary institutions. (table 5) 
Table 1. Characteristics of study respondents.

\begin{tabular}{ll}
\hline Characteristics & $\mathbf{N}=\mathbf{1 4 8}(\mathbf{\%})$ \\
\hline Age (Mean \pm SD) years & $\mathbf{3 8 . 7}(\mathbf{9 . 5})$ \\
Gender & $97(66)$ \\
Female & $51(34)$ \\
Male & $131(89)$ \\
Professional Cadre & $17(11)$ \\
Doctor & $2(1.4)$ \\
Nurse & $34(23)$ \\
Duration of Practice & $33(22.3)$ \\
$<1$ year & $79(53)$ \\
$1-4$ years & \\
5-10 years & $46(31)$ \\
$>10$ years & $102(69)$ \\
Type of Practice & \\
Private & $54(36)$ \\
Public & $94(64)$ \\
Level of Practice & \\
Secondary & $74(50)$ \\
Tertiary & $74(50)$ \\
Previous Experience of Disease Outbreak & \\
Yes & $99(66.9)$ \\
No & $15(10.1)$ \\
Distribution of Respondent by Zone & $9(6)$ \\
South West & $9(6)$ \\
South-South & $3(2)$ \\
South East & $13(9)$ \\
North West &
\end{tabular}

Table 2. Knowledge and practice of IPC.

\begin{tabular}{ll}
\hline Characteristics & N (\%) \\
\hline Presence of Infectious Disease Unit & $100(68)$ \\
Yes & $48(32)$ \\
No & \\
Infectious Disease Policy & $89(60)$ \\
Yes & $59(40)$ \\
No & \\
Training & $63(43)$ \\
Yes & $85(57)$ \\
No & \\
Frequency of Trainings [n=63] & $19(30)$ \\
Annually & $7(11)$ \\
Bi-Annually & $27(43)$ \\
Quarterly & $10(16)$ \\
When Necessary & \\
IPC Policy and Facilities Support Rating & $20(14)$ \\
Good & $111(75 \%)$ \\
Fair & $17(11)$ \\
Poor & $146(99)$ \\
Knowledge of Steps of IPC & $2(1)$ \\
Yes & \\
No &
\end{tabular}

Table 3. Knowledge and Preparedness For COVID-19.

\begin{tabular}{ll}
\hline Characteristics & \\
\hline Aetiology COVID-19 & $144(97)$ \\
SARS-CoV-2 & $2(1.5)$ \\
Retrovirus & $2(1.5)$ \\
Rhinovirus & \\
Incubation Period [Days] & $143(96.6)$ \\
$2-14$ & $3(2)$ \\
$7-28$ & $2(1.4)$ \\
21 & \\
\hline
\end{tabular}




\begin{tabular}{ll}
\hline Characteristics & \\
\hline Symptomatology & $20(14)$ \\
Symptomatic only & $128(86 \%)$ \\
Asymptomatic and Symptomatic & \\
Similitude to Common Childhood illnesses & $138(93)$ \\
Yes & $10(7)$ \\
No & \\
COVID-19 Diagnostic Criteria & $132(89)$ \\
Good & $16(11)$ \\
Poor & $35(24)$ \\
Knowledge of care of children infected with SARS- CoV-2 & $113(76)$ \\
Good & $113(76)$ \\
Poor & $35(24)$ \\
Availability of COVID-19 Policy & $33(29)$ \\
Yes & $62(55)$ \\
No & $18(16)$ \\
Respondent Rating on COVID-19 Policy & \\
Good & \\
Fair & \\
\hline
\end{tabular}

Table 4. Association between type of practice and preparedness.

\begin{tabular}{|c|c|c|c|c|c|c|}
\hline & \multicolumn{3}{|c|}{ TYPE OF PRACTICE } & \multirow[t]{2}{*}{ O. R. } & \multirow[t]{2}{*}{ C. I. } & \multirow[t]{2}{*}{ p-value } \\
\hline & & Public n (\%) & Private n (\%) & & & \\
\hline \multirow[t]{2}{*}{ Children Emergency Ward/Room } & Yes & $83(81)$ & $23(50)$ & 4.4 & $2.0-9.4$ & 0.01 \\
\hline & No & $19(19)$ & $23(50)$ & & & \\
\hline \multirow[t]{2}{*}{ Isolation ward } & Yes & $77(75)$ & $19(41)$ & 4.4 & $2.1-9.2$ & 0.01 \\
\hline & No & $25(25)$ & $27(59)$ & & & \\
\hline \multirow[t]{2}{*}{ IDU team } & Yes & $82(80)$ & $18(39)$ & 6.4 & $3.0-13.7$ & \\
\hline & No & $20(20)$ & $28(61)$ & & & $<0.01$ \\
\hline \multirow[t]{2}{*}{ COVID team } & Yes & $81(79)$ & $14(30)$ & 6 & $2.8-12.9$ & \\
\hline & No & $21(21)$ & $32(70)$ & & & $<0.01$ \\
\hline \multirow[t]{2}{*}{ COVID policy } & Yes & $79(77)$ & $34(74)$ & 1.2 & $0.5-2.7$ & 0.64 \\
\hline & No & $23(23)$ & $12(26)$ & & & \\
\hline \multirow[t]{2}{*}{ COVID plan } & Good & $20(25)$ & $13(38)$ & 0.5 & $0.2-1.3$ & 0.17 \\
\hline & Not good & $59(75)$ & $21(62)$ & & & \\
\hline \multirow[t]{2}{*}{ COVID equipment } & Good & $14(14)$ & $6(13)$ & & & \\
\hline & Not good & $88(86)$ & $40(87)$ & 1.1 & $0.4-3$ & 0.91 \\
\hline \multirow[t]{2}{*}{ IPC knowledge } & Good & $79(77)$ & $31(67)$ & 1.7 & $0.8-3.6$ & 0.19 \\
\hline & Not good & $23(23)$ & $15(33)$ & & & \\
\hline \multirow[t]{2}{*}{ COVID diagnostic criteria } & Good & $35(34)$ & $12(26)$ & 1.5 & $0.7-3.2$ & 0.32 \\
\hline & Not good & $67(66)$ & $34(74)$ & & & \\
\hline \multirow[t]{2}{*}{ Knowledge (COVID care) } & Good & $25(25)$ & $10(22)$ & 1.2 & $0.5-2.7$ & 0.71 \\
\hline & Poor & $77(75)$ & $36(78)$ & & & \\
\hline
\end{tabular}

Table 5. Association between level of practice and preparedness.

\begin{tabular}{|c|c|c|c|c|c|c|}
\hline & \multicolumn{3}{|c|}{ LEVEL OF PRACTICE } & \multirow{2}{*}{ O. R. } & \multirow{2}{*}{ C. I. } & \multirow{2}{*}{ p-value } \\
\hline & & Tertiary n (\%) & Secondary n (\%) & & & \\
\hline \multirow[t]{2}{*}{ Children Emergency Ward/Room } & Yes & $82(87)$ & $24(44)$ & 8.5 & $3.8-19.2$ & $<0.01$ \\
\hline & No & $12(13)$ & $30(56)$ & & & \\
\hline \multirow[t]{2}{*}{ Isolation ward } & Yes & $71(76)$ & $25(46)$ & 4.1 & $2.0-8.4$ & 0.01 \\
\hline & No & $23(24)$ & $29(54)$ & & & \\
\hline \multirow[t]{2}{*}{ IDU team } & Yes & $83(88)$ & $17(31)$ & 16.4 & $7.0-38.5$ & $<0.01$ \\
\hline & No & $11(12)$ & $37(69)$ & & & \\
\hline \multirow[t]{2}{*}{ COVID team } & Yes & $77(82)$ & $18(33)$ & 9.1 & $4.2-19.6$ & $<0.01$ \\
\hline & No & $17(18)$ & $36(67)$ & & & \\
\hline \multirow[t]{2}{*}{ COVID policy } & Yes & $75(80)$ & $38(70)$ & 1.7 & $0.8-3.6$ & $<0.01$ \\
\hline & No & $19(20)$ & $16(30)$ & & & \\
\hline \multirow[t]{2}{*}{ COVID plan } & Good & $20(27)$ & $13(34)$ & 0.7 & $0.3-1.6$ & 0.40 \\
\hline & Not good & $55(73)$ & $25(66)$ & & & \\
\hline \multirow[t]{2}{*}{ COVID equipment } & Good & $13(14)$ & $7(13)$ & 1.1 & $0.4-2.9$ & 0.88 \\
\hline & Not good & $81(86)$ & $47(87)$ & & & \\
\hline \multirow[t]{2}{*}{ IPC knowledge } & Good & $72(77)$ & $38(70)$ & 1.4 & $0.6-2.9$ & 0.40 \\
\hline & Not good & $22(23)$ & $16(30)$ & & & \\
\hline \multirow[t]{2}{*}{ COVID diagnostic criteria } & Good & $34(36)$ & $13(24)$ & 1.8 & $0.8-3.8$ & 0.13 \\
\hline & Not good & $60(64)$ & $41(76)$ & & & \\
\hline
\end{tabular}




\begin{tabular}{|c|c|c|c|c|c|c|}
\hline & \multicolumn{3}{|c|}{ LEVEL OF PRACTICE } & \multirow[b]{2}{*}{ O. $\mathbf{R}$. } & \multirow[b]{2}{*}{ C. I. } & \multirow{2}{*}{ p-value } \\
\hline & & Tertiary n (\%) & Secondary n (\%) & & & \\
\hline Knowledge (COVID care) & $\begin{array}{l}\text { Good } \\
\text { Poor }\end{array}$ & $\begin{array}{l}23(24) \\
71(76)\end{array}$ & $\begin{array}{l}12(22) \\
42(78)\end{array}$ & 1.1 & $0.5-2.5$ & 0.76 \\
\hline
\end{tabular}

\section{Discussion}

The symptomatology of the SARS-CoV-2 pandemic is similar to common childhood illness; thus, infected children could be "silent transmitters" of the disease to family members and their health care providers. Therefore, this raises questions on the level of preparedness, awareness of the child health facilities, and health care providers in adopting measures at combatting the COVID-19 pandemic.

The study revealed that most paediatric health care facilities had an infectious disease unit with existing policy but a fair rating on the preparedness towards combating disease outbreaks, despite being aware of steps in IPC. The study showed that a significant proportion of the child health care providers had satisfactory knowledge of the SARS-CoV2 infection and understood the similarity in symptomatology to common childhood illness. The preparedness levels with respect to the availability of resources towards containing COVID-19 was fair.

The reason why most of the health care facilities have an IDU with relatively good health care policy is that they are secondary and tertiary levels of care. This is in contrast to earlier reports of poor preparedness of health care facilities (Ugaharo et al. [16] in Nigeria, Yayi et al. [17] in Uganda, and Daugherty et al. [18]) in previous disease outbreaks in the past. The report of fair ratings despite the existence of policy however is in concordance with previous works $[16,19,20]$. This further buttress the fact that a standard IDU is not only about policy, but the availability of resources and training of health care workers $[\mathrm{HCW}]$ to operationalize the policy. Furthermore, most of the participants showed a good understanding of the steps in IPC. This could be alluded to the years of medical experience, in addition to the facilities predominantly tertiary and secondary healthcare facilities. This finding is similar to reports by previous works demonstrating the knowledge competence of $\mathrm{HCWs}$ on IPC $[16,21,22]$. The value of a good overall knowledge of HCWs is of significant importance in all spheres of disease identification, control, and management.

Several outbreaks of infectious diseases have occurred recently, from Ebola, cholera, Lassa fever, HIV/AIDS to monkeypox in Nigeria, including the current global pandemic of SARS-CoV-2. The knowledge of HCWs about the spread and symptoms of SARS-CoV-2 infection is high, and this could indicate the level of their clinical experience and the need to be abreast of information during disease outbreaks. However, only $57 \%$ of HCWs were aware of the diagnostic criteria due to the novelty and non-specificity of the disease.

The fair assessment of facility preparedness expresses the continued need for HCFs to provide universal precautionary measures, control programs, disease surveillance, and human resource development to combat the current pandemic or any other epidemic in the future. This is in concordance with previous research depicting similar ratings of facility preparedness towards outbreaks of communicable diseases in previous works $[16,19,20]$. This finding shows the need for HCF to continuously evaluate the preparedness towards present and future epidemics.

\section{Conclusion}

The study findings showed that the majority of Healthcare workers had a good knowledge of the SARS $\mathrm{CoV}-2$ infections and management as well as the knowledge of IPC within established Infectious Disease Units in the various Paediatric healthcare Institutions. However, less than $50 \%$ of the health care workers had regular training to enhance their skills and level of preparedness towards combating SARS-CoV-2 infection among other infectious disease outbreaks. Also, the HCWs rated the IPC policy document as fair because it did not capture all of the thematic areas with regards to Infection Control. Thus, the disparity between the level of preparedness, skills acquisition, and policy rating could undermine the effectiveness and efficiency of combating infectious disease outbreaks and outcomes.

In conclusion, there is the need to harmonize Infection Control practice activities in pediatric healthcare Institutions through routine and refresher training; creating and updating guidelines; developing capacity, monitoring, and evaluation as well as managing COVID-19 cases and other epidemics in the pediatric population to enhance ensure optimal standards in the various Institutions.

\section{Limitations}

This was an online, cross-sectional study to evaluate the preparedness of HCWs and HCFs dedicated to the care of children. In addition, the views of the parents/caregivers about the capacity of the HCWs and HCFs were not assessed in this study.

\section{Acknowledgements}

We appreciate our numerous health care workers at the frontline of combating the COVID-19 pandemic and those who took out time to respond to our questionnaire. Appreciation goes to the entire staff of the Clinical Sciences Department of the Nigerian Institute of Medical Research for their unwavering attitude to the care and management of clients under their watch. 


\section{References}

[1] World Health Organization. Zoonoses. Geneva: WHO; 2016. Available at: http://www.who.int/zoonoses/diseases/en/.(accessed April 5, 2020).

[2] World Health Organization. Ebola virus disease outbreak. Geneva: WHO; 2016. Available at: http://www.who.int/csr/disease/ebola/en/. (accessed April 5, 2020).

[3] World Health Organization. Zika virus. Geneva: WHO; 2016. Available at http://www.who.int/mediacentre/factsheets/zika/en/.(accessed April 5, 2020).

[4] Mathis M. Briand S. Prentice T. Emerging and re-emerging infectious threats in the 21st century. Wkly Epidemiol Rec. 2015; 90: 238-244.

[5] Bloom DE, Cadarette D. Infectious Disease Threat in the Twenty-First Century; Strengthening Global Response. Front Immunol. 2019; 10 (549): 1-12[Open Access, accessed April 4, 2020).

[6] Leigh J, Moon S, Gracia E, Fitzgerald G. Is Global Capacity to Manage Outbreaks Improving? -An Analysis. Global Health Working Paper Number 17/2018 [accessed April 2020].

[7] World Bank Group. Operational Framework for Strengthening Human, Animal, and Environmental Public Health Systems at their Interface. World Bank Report Number: 122980-GLB. Available at: http://documents.worldbank.org/curated/en/703711517234402 168/Operational-framework-forstrengthening-humananimal-and-environmental-public-health-systems-at-theirinterface [Accessed April 2020].

[8] World Health Organization. Naming the coronavirus disease (COVID-19) and the virus that causes it. Available at: https://www.who.int/emergencies/diseases/novel-coronavirus2019/technical-guidance/naming-the-coronavirus-disease(covid-2019)-and-the-virus-that-causes-it (Accessed: 4 April 2020).

[9] Hui, D. S. Azhar EI, Madani TA, Ntoumi F, Kock R, Dar O et al. (2020) 'The continuing 2019-nCoV epidemic threat of novel coronaviruses to global health - The latest 2019 novel coronavirus outbreak in Wuhan, China', International Journal of Infectious Diseases, pp. 264-266. doi: 10.1016/j.ijid.2020.01.009.

[10] World Health Organization. Coronavirus disease (COVID-19) Situation Dashboard, World Health Organization. Available at: https://experience.arcgis.com/experience/685d0ace521648f8a 5beeeee1b9125cd (Accessed: 6 April 2020).
[11] $\mathrm{Wu} \mathrm{Z,} \mathrm{McGoogan} \mathrm{JM.} \mathrm{Characteristics} \mathrm{of} \mathrm{and} \mathrm{Important}$ Lessons from the Coronavirus Disease 2019 (COVID-19) Outbreak in China. Summary of a Report of 72314 Cases from the Chinese Center for Disease Control and Prevention. JAMA. 2020. Accessed at https://jamanetwork.com/ on $04 / 06 / 2020$.

[12] The World Bank. Nigeria Overview. Available at https://www.worldbank.org/en/country/nigeria.

[13] Nigerian Centre for Disease Control [NCDC]. COVID-19 Update.ncdc.gov/COVID-19 NCDC. GOV. NG Accessed April 6, 2020].

[14] National Population Commission (NPC) [Nigeria] and ICF. 2019. Nigeria Demographic and Health Survey 2018. Abuja, Nigeria, and Rockville, Maryland, USA: NPC and ICF.

[15] Shen K, Yang Y, Wang T, Zhao D, Jiang Y, Jin R et al. Diagnosis, treatment, and prevention of 2019 novel coronavirus infection in children: experts' consensus statement. World Journal of Pediatrics. 2020: 1-7.

[16] Ughasoro, MD, Esangbedo DO, and Udorah IM. Health-Care Workers' Perspectives on Preparedness of Health-Care Facilities for Outbreak of Communicable Diseases in Nigeria: A Qualitative Study. Am. J. Trop. Med. Hyg. 2019: 100 (4): 1022-1028 doi: 10.4269/ajtmh.18-0404.

[17] Yayi A, Laing V, Govule P, Onzima RADDM, Rogers Ayiko, 2015. Performance of epidemic prevention, preparedness and response in West Nile region, Uganda. Int J Public Health Res 3: $228-233$.

[18] Daugherty EL, Carlson AL, Perl TM, 2010. Planning for the inevitable: preparing for epidemic and pandemic respiratory illness in the shadow of H1N1 influenza. Clin Infect Dis 50: $1145-1154$.

[19] Ogoina D, Pondei K, Adetunji B, Chima C, Isichei C and Gidado Knowledge, attitude and practice of standard precautions of infection control by hospital workers in two tertiary hospitals in Nigeria. Journal of Infection Prevention2015, Vol. $16 \quad$ (1) $16-22$ doi: $10.1177 / 1757177414558957$.

[20] Brisibe SFA, Ordinioha B, Gbeneolol PK. Knowledge, attitude, and infection control practices of two tertiary hospitals in PortHarcourt, Nigeria. NJCP. 2014. 17 (6): 691-695.

[21] Tour EA, Traor EF, Sako F, Delamou A, Tonguino F, Sylla D, Bangoura M, Barry M, Cisse M, Vanhems P, 2016. Knowledge, attitudes, and practices of healthcare workers on Ebola virus health-care facilities preparedness for disease outbreak 1027 disease in Conakry, Guinea: a cross-sectional study. J Public Health Epidemiol 8: 12-16.

[22] Okechukwu EF and Modteshi C. Knowledge and practice of standard precautions in public health facilities in Abuja Nigeria. International Journal of Infection Control. 2012; 8: 17. 